\title{
Universal and Culture-Specific Conceptualization of Anger in Russian*
}

\author{
Song, Eun-Ji*
}

\section{Introduction}

Emotion concept used to be treated as an arbitrary and irrational semantic domain escaping any linguistic research. Considering that emotion is fundamentally introspective concept only accessible to the experiencing subject and is basically culture-dependent concept(Russell 1991), it is understandable that emotion concept has long been an alienated subject matter in linguistic semantics. Only through cognitive approach to language and conceptual metaphor theory, emotion concepts came to be accounted for as having coherent semantic substance. Kövecses and Lakoff's pioneering research on 'anger' in English(Lakoff 1987) shows how emotionality and rationality are not mutually exclusive and how emotion concepts are experientially grounded. Through cognitive approach to language and emotion concept, the traditional reason-emotion binarism and cognition-affect dichotomy came to be reexamined.1)

Emotion, as a linguistic concept, since it is based on subjective inner

* This research was funded by Korean Research Foundation (KRF-2004-074-AM0060). ** 서울대학교 노어노문학과 교수

1) There is no word corresponding to 'emotion' in Russian and Russian word chuvstuo(chuvstuovat') corresponds to 'feeling'. Emotion is cognitively based feeling, hence a more complex concept. In Russian one can say both chuvstuo goloda and chuvstuo styda(Wierzbicka 1999). Further, Wierzbicka(1992a, 1992b, 1999, Бежбицкая 2001) includes 'feel' in the semantic metalanguage, or semantic primitives. 
feeling of the experiencer inaccessible from observer's point of view and is apparently unstructured from the investigator's point of view, was a controversial topic for semanticists. Further, emotion concepts have been regarded as too arbitrary and variable for serious linguists' research. Explicating emotion concepts in a given language and cultural context through any representative natural language is itself a dangerous pitfall, since any natural language emotion concept is saturated with the sociocultural values. The seemingly unstructured emotion lexicon can be better discussed through cognitive approach to language. Here, metaphor and metonymy can function as "semantic primitives" in that they reveal human conceptualization of emotion concepts in non-arbitrary way. Cognitive linguistics is interested in conceptualizations, not linguistic expressions or references per se, and metaphor or metonymy can be the main cognitive instruments for understanding emotion concept.

There are a fundamental question to address. Are there universal or focal, central emotions in human mind, just like color?2) Or are emotions mere arbitrary sociocultural product of a given speech community? The most plausible thesis I shall subscribe to is Kövecses et al (2003). They combine universal experientialism and cultural relativism. Through this eclectic, but balanced approach, I hope to show that emotion concepts have common core meanings based on human bodily experience and that they have at the same time sociocultural semantic specificities.3)

2) Color and emotion are different in that focal colors are universal, but emotion concept is culture-dependent. In both categories, however, it is tue that linguistically articulated concepts facilitate cognition.

3) According to Kövecses(1995, 2000), the meaning of emotion concept can be investigated from several approaches, such as "label" view, "core meaning" view, "dimensional" view, "implicational" view, "prototype" view, "social constructionist" view and "embodied cultural prototype" view. These approaches are not mutually exclusive, but like Kövecses, I subscribe to the last view, embodies cultural prototype view. According to this view emotion concept is both motivated by human body and produced by socio-cultural environment. Thus emotion concept is a complex of physiology(nature) and culture. As I 
This study investigates the anger emotion concept in Russian and I hope to show how it is conceptualized through metaphor or metonymy as well as collocations. Further the study shows for the emotion concept, metonymy evoking a cultural frame is deeply embedded in its metaphors. The conflation and interaction of metonymy and metaphor in emotion concept and the important role of cultural frame evoked by metonymy should be noted. The conceptualization of 'anger' in Russian has both language-universal and culture-specific semantic features and especially the latter shows that Russian frame or prototype for the anger emotion is significantly different from that of English anger concept. Russian anger concept is not limited to moral balancing, i.e. a restitution, retribution, reciprocation. It can also be a proactive presentational form of social behavior that experiencing self may exploit in his/her benefit for securing freedom, autonomy, or justice.

\section{Approaching Anger in Russian}

\section{1. 'Anger' in Prototypical Scenario}

'Anger' is a basic-level descriptive emotion concept along with such emotion concepts as 'love', 'sadness', 'fear', 'joy', etc, and is more basic than 'irritation', 'fury', 'rage', 'wrath', 'indignation', etc. 'Anger' is more prototypical emotion, as compared to 'pride', 'hope', or 'shame'. This emotion, together with 'sadness', 'fear', etc. is usually believed to be in the negative category as opposed to positive category, which includes 'happiness', 'joy', etc.

show in this paper, anger concept in Russian reveals both panhuman aspects and culture-specific modelling. 